\title{
Who monitors the mentors?
}

\author{
Mladen M Kuftinec \\ Professor and Director of Orthodontics (retired) \\ New York University College of Dentistry \\ New York, US \\ ${ }^{\star}$ Corresponding author: \\ miki.kuftinec@nyu.edu \\ Tel.: + 017277893765
}

Received: 14 September 2015

Accepted: 4 October 2015

Key words: Mentoring - Monitoring

- Metrics - Medicine.

\section{Who are mentors? What are their roles?}

In a global sense it is not difficult to agree that anyone wo contributes to the growth and development be it somatic, intellectual, educational or any other form is a mentor. There is no argument that the parents, teachers, coaches, special skill instructors and other similarly engaged individuals can collectively be viewed as mentors They probably instill more important formative traits than any designated mentors, in an individual's mature life. No intention to praise or criticize the name selection for these early mentors, even though other authors may find this a critical distinction (1). There are several recent articles, elaborating on various levels and/or environments of the formal mentoring processes in science, particularly in biomedical arena (2), similarly (3) offering a novel model of mentoring in biomedical sciences, arriving to concepts of viewing certain metrics, as well as the envi- ronmental dynamics of the mentoring process. It is worth mentioning that the current developmental sociologists view the role of family, namely the early life mentoring by the parents and grandparents, as having a critically important value.

Thus for the purpose of this editorial I will define mentors as individuals who prepare those selected or assigned to them to grow, get better and ultimately excel above and beyond their mentors' knowledge, skills and ability in a particular area or field. A failure of existence of such a system may be paramount to no progress, perhaps stagnation and potentially even regression in a particular field. In fact, this writer is on a record for stating that a lack of mentors, specifically in the field of orthodontics, inevitably would lead to a crisis in orthodontic education and leadership (4).

In my many years of teaching and acting as an educational administrator, I have never met, or even heard of a person whose job title was "mentor". Instead, the various mentoring functions are typically taken by, or given to the "chiefs" - Department Heads, Directors, Deans and similar administratively titled individuals. In some, but not many, job descriptions of these chiefs the task of mentoring members of their team is listed, however the specific tasks of doing this routinely and in a given time frame, are not included. If this task was given, it would be logical to also find the specific criteria how successes of performing in this assign- 
ment are measured. All to me available documents are sadly lacking any such metrics.

If we reflect on our own professional development, recalling who our memorable mentors were, it is likely that we would come up with a relatively modest person, who managed to help us "see our way better". Probably it would not be a world-wide recognized or global expert, but the person who had the time and interest in us, whom we consulted when we didn't know the questions. Even if you achieved a high degree of success in your own field, chances are that your mentor remained in the background, named on your thesis or a significant paper's acknowledgments page.

Conversely, it is a bit difficult to know what one may expect to gain from their mentor, because the rules are seldom made known to either party (1). By now the reader may have perceived a hint that the entire process of mentoring, in order to move in a positive direction, must have some metrics or measures for evaluating the mentoring effectiveness developed and accepted. We should be prepared to value mentoring activities with the same yardstick that we measure the number and importance of our published work, the numeric value of our research grants, frequency of our invited lectures and awards given for our scientific opus. Best to my knowledge, such equalizers have not been developed. It is the high time to do so!

In an institution where I was appointed in my early academic career as a faculty, a modest and entirely voluntary student mentoring program was in place. At the start of their freshman year, during the orientation meeting, the students were asked if they were interested in being assigned to a particular faculty, who would act as their academic mentors. I "took" 16 students, offered to see them on the basis of the open door policy. I also scheduled a meeting, where we would introduce ourselves to each other.
Of my 16 mentees 4 came to the meeting, 2 more responded to my follow up mail, I stayed in touch for 3 years with one student, the one who was interested in applying for a program that I was directing. An interesting part of the story is that when the supposedly participating students were asked, at the end of the year, to fill a form, giving feedback evaluating their individual experience with the program, as well as the effectiveness of their mentor, all 16 responded. They all stated that I was an excellent mentor and that I helped them throughout the year. Again, this included the students that I have not seen that entire year!

One question asked what was good and attractive, and also what was not good about the existing program. The most common answer was the knowledge that the mentor was "there" and could be reached within a reasonably short time, when needed.

No comments are needed.

\section{An experiment with reality}

During the periodic evaluations of administrators, one of the common remarks was that the majority of them have not actively worked on developing their successors. It was not too difficult to equate this observation with the lack of proper mentoring. In the area where this author spent working during his last 20 plus years, prior to his retirement [New York City area], there are 12 academic institutions, colleges or universities, offering medical and/or dental programs, leading to doctoral degrees.

In early 2000s, these schools employed several thousand faculty, more than 1000 employed full time. We estimated that at least $5 \%$ of these, or somewhere between 50 and 100 faculty were in a "chief"s" position. These are assumed to have had not only the leading administrative roles, but were also the prime source of academic mentoring. 
During a popular and always well attended local meeting, an informal agreement was made for the "chiefs" who had any written mentoring guidelines or protocols, to share them with interested colleagues. We at New York University Medical Center, comprising of the College of Medicine and the College of Dentistry and Nursing, accepted the task of collecting, tabulating and then distributing the fruits of this somewhat naïve idea. We expected and were prepared to process several hundred of documents. Only 26 were received, more than half of these from our two NYU colleges. Not totally discouraged by this painful lack of interest, we carefully read and processed the few we received.

The summary was sent to all who contributed and it was informally made known that essentially any of the non-contributors could obtain the document, but on the basis of nomina odiosa. So what was contained in the received documents? First and perhaps the most relevant - mentoring of young faculty on their way to becoming future mentors is not a high priority of the chiefs! Most of the ones who report some form of formal mentoring did so because they received specific directives from the recommendations of the accrediting bodies and not from their administrative supervisors [typically the Deans]. One other interesting and repeating situation described a formal mentoring of a young, promising faculty, groomed to become the Departmental Head. Alas, an offer from the private practice sector, bearing the double income, prevailed and took that targeted for academic greatness individual in a different direction. The moral of that story is that it is difficult to ignore the cost of mentoring the young faculty, particularly when the outcome is negative, not because the process was inadequate, but because attractions of larger pay is nearly impossible to out-duel, even when both the protagonists and the process excel.

\section{Could we agree on how the mentor's effectiveness is measured?}

This is, admittedly, the hard part. I suppose that if it were easy, someone would have, by now, developed sensible metrics. Why is this not an easy task? It is probably fair to state that no two mentees require the same form or degree of mentoring. This, however, can be said for the task and obligation of writing and publishing. This is true for many other forms or aspects of our functionality. One not too difficult measure to implement is the feedback or evaluation of those who were being mentored. Of course this would be a very subjective process, easily seen as retaliatory. Let us not forget that any judging or comparing performances, be it in sports, theatrical arts and certainly in sciences is already subjected to measuring and judging through our personally biased views.

The continuous scales or axes have been developed by statisticians and sociologists, where they manage to "measure" extremely subjective or personal sensations, for instance pain, anxiety, sorrow, happiness and others (5). Could we project that similar methods could be developed for the subjective measuring of the mentoring process and its effectiveness? Next powerful measure would be following the mentor generated plan of action. At some point in time, call it the T1, a plan, containing the final outcome prediction, but also the intermittent, say 6 months or one year intervals, namely T2, then T3 and so on to Tn. It would seem that the temporal element must be added as a crucial part of this evaluation. Are there any predictable problems with this? Of course! Who will hang the proverbial bell to the cat's neck? That is to say, who will look at such a 'contract' and say: NO, this is not enough? Or conversely: you are aiming too high, this is unrealistic! 


\section{Controlling the mentors (It is a hard work, but someone must do it!)}

Early on in my career I was asked these questions: Do you know what mentoring is? Do you think you can be an effective mentor? How does one answer that? Surely I believed that I could and I would. It occurred to me, however, to ask how I would know if I was doing a good job of mentoring my staff and my students. The metrics needed to determine my effectiveness of mentoring were not presented.

Equally, or even more challenging was when, two decades later, I was appointed to a administrative committee, changed with evaluating the mentoring effectiveness of my peers, Deans, Department Heads and Program Directors. No working rules were given and it was clearly stated that we, the committee members, were expected to decide how to evaluate the mentoring skills and effectiveness, fully aware of the possibility that those who we evaluated today may be evaluating us tomorrow. We asked the respective chiefs to submit a brief written narrative of their mentoring actions. Submitted responses included "regular meetings to discuss the future plans", "some success in academic rank promotion and tenure", "taking individual member out for a meal, a play or a concert, during which time the member's plans were discussed". Tricky and perhaps even risky practice clearly not recommended as a routine tool of mentoring. However, the short of it was that we have not discovered any existing tools, nor did we create a "white paper" containing the easy to understand and apply metrics. Conversely, we have submitted a list of the basic parameters for the evaluation of mentoring actions (6).

It was identified that:

1. In order to move forward, the mentoring process must exist;

2. Define the roles of chiefs and mentors;

3. Where needed, separate the two roles;
4. Introduce the time dimension, set it along with the quality and quantity;

5. Provide the mechanism for the negative evaluation; be prepared and willing to deal with it!

\section{What are or can be incentives to be a mentor?}

Even though one could expect substantial territorial (e.g. location of the school or institution) and socio-economic differences, I suspect that incomes and other material incentives for mentors are quite similar. Perhaps this needs to be restated by saying that those who devote a significant part of their job to mentoring, typically don't get wealthy from it. In the American society the somewhat sarcastic expression that mentoring is not a billable procedure, fairly depicts the choices that the top people, the high ranking experts in their field elect to provide the billable services, such as patient care, contact hours of teaching, guest lecturing and similar.

There must be some other, non-tangible benefits to mentoring. One that readily comes to mind is the opportunity to travel. This is either because of the mentor's own scientific reputation and name recognition, or thanks to invitations of those who we monitored during their growing phases.

It is also true that the mentors are often invited to serve on the thesis committees, which is in many places separately paid. Therefore the research and thesis committee membership may supplement mentors incomes, some time by a sizable margin. [ref.: Personal communication with numerous Deans in many countries on several continents]. As a person with clinical specialty training, who also served as a mentor to literally hundreds of students and young faculty, I can personally vouch that it is easier to make a comfortable living by seeing patients, rather than advising my mentees. 


\section{Concluding remarks}

At the end of this exercise the reader is justified to ask what I really think of and how strongly I support the academic mentoring. I'll try to make myself clear. Most of discussion in this issue concerns the field of medicine and its related scientific basis. I'm assuming that my own thought coming largely from the dental field, will help enlarge the playing field, while clearly showing that the grass is of the same color and quality. I will further assume that the situation is not all that different in other scientific areas. The prevailing conditions and practices are too similar to believe that things are different.

Allow me to take a stab in a diametrically opposite direction. Suppose that a strict governmental decree is announced, entirely prohibiting any form of mentoring. Who would be affected the most? Whose livelihood would be disturbed the most?

I certainly don't claim to be a deciding arbiter, but if I had to, this is how I would answer. First, the Earth would not stop from spinning, Saturday will still follow Friday. In other words, the world could survive such a ruling. I dare guess that in most of the biomedical fields mentors would readily and easily refocus on other functions, with which they are more than familiar. So these "former mentors" would surely survive. What then happens when many of the current mentors age, retire and die?

I envision an alternate system to emerge, one whose parameters have not been yet developed. This, however, brings me to the verses of the brilliant Croatian poet and writer, Miroslav Krleža: "Never is such that it isn't somehow, and never will be that it won't be somehow".

Many of the suggested tenets should be formally accepted and put to task. The optimist in me is screaming that, if the Greeks left their legacy defining the terminology of actions and processes that we engage in, including the definition of the mentorship, perhaps the future biomedical scientists will come up with ways to develop their successors. It is unfortunate that we cannot consult with Krleža as to how such things will happen.

Conflict of interest: The author declares that he has no conflict of interest.

\section{References}

1. Sambunjak D, Marusić A. Mentoring: what's in a name? JAMA. 2009;302(23):2591-2.

2. Marusic M. Cross-cultural common denominators of the mentoring in biomedicine. Acta Med Acad. 2015; 44(1):75-6

3. Sambunjak D. Understanding wider environmental influences on mentoring: Towards an ecological model of mentoring in academic medicine, Acta Med Acad. 2015;44(I)47-57.

4. Kuftinec MM. Crime and punishment. Am J Orthod Dentofacial Orthop. 1993;103(4):25A.

5. Turpin DL. AAO coordinates specialties to recruit and retain dental faculty. Am J Orthod Dentofacial Orthop. 2002;121(1):1.

6. Kuftinec M. Orthodontic faculty. Am J Orthod Dentofacial Orthop. 2002;121(6):15A. 